\title{
LECTINS (HEMAGGLUTININS) IN THE GUT OF THE IMPORTANT DISEASE VECTORS
}

\author{
GRUBHOFFER L.*, HYPŠA V.* \& VOLF P.**
}

\section{Summary :}

The review is devoted to the gut lectins/hemagglutinins of the following representatives of important disease vectors: ticks, kissing-bugs, mosquitoes, sandflies and tsetse flies. The paper surveys the recent knowledge on these carbohydrate binding factors with respect to their structural and functional properties, and their significance for pathogen/parasite transmission by the blood-sucking arthropods. Recent results suggest that in most vectors the gut lectin activities are blood-meal enhanced, might participate in blood-meal processing and digestion and could serve as antibacterial and antiparasitic agents.

KEY WORDS : lectins, hemagglutinins, gut, blood-sucking arthropods, vectors.

\section{GENERAL PART}

\section{NON-COVALENT INTERACTIONS \\ IN VECTOR-PATHOGEN RELATIONSHIPS}

$\mathrm{L}$ ectins as the proteins with binding affinity for carbohydrate molecules take part mainly in the tions are one-saccharide interactions. These interactions are one of those participating in both effector and regulatory processes in organisms including tissue systems of blood-sucking arthropods as vectors of the causative agents of diseases. Besides this kind of interactions, other interaction principles based on different binding/ non-binding activities are employed in an extracellular environment (soluble factors) or on a surface of the cells (peripheral/integral proteins). Recently, protein-protein interactions have been studied in mechanisms of cell adhesion (integrins $v s$ adhesins), and so-called scavenger proteins have been described as representatives of the protein-lipid/phospholipid interactions (for review Pearson, 1996).

\footnotetext{
* Institute of Parasitology, Academy of Sciences of the Czech Republic, Faculty of Biological Sciences, University of South Bohemia, Branišovská 31, 37005 České Budějovice, Czech Republic.

** Department of Parasitology, Charles University, Viničná 7, 12840 Prague, Czech Republic.

Correspondence: Libor Grubhoffer.

Tel: 0042-38-41158, Fax: 0042-38-47743

E-mail: liborex@paru.cas.cz
}

Résumé : LECTINES (hÉMAGgLuTININES) DE L'INTESTIN DES PRINCIPAUX VECTEURS

La revue est consacrée aux lectines/hémagglutinines de l'intestin des principaux vecteurs de maladies: tiques, triatomes, moustiques, phlébotomes et mouches tsé-tsé. L'article fait le point des connaissances de ces facteurs liants des carbohydrates quant à leurs qualités structurales et fonctionnelles et leur caractère significatif en matière de transmission pathogène/parasite par les arthropodes hématophages. Les résultats récents montrent que chez la plupart des vecteurs l'activité des lectines de l'intestin est renforcée par la succion de sang, peut participer au processus de digestion du sang sucé et peut servir d'agent antibactérien et antiparasitaire.

MOTS CLÉS : lectines, hémagglutinines, intestin, arthropodes hématophages vecteurs.

\section{LECTINS AND PROTEIN-CARBOHYDRATE} INTERACTIONS: FUNDAMENTAL FEATURES

Lectin research began more than 100 years ago in 1888 and has been linked to the doctoral thesis of Herman Stilmark at the University of Dorpat dealing with agglutinins of the seeds of castor bean Ricinus communis (Franz, 1988; Sharon \& Lis, 1988). Further investigation of proteins able to agglutinate red blood cells (RBCs) has significantly been improved by experimental techniques, analytical and preparative methods in hematology, immunology, virology, and lately even in parasitology and molecular biology (Sharon \& Lis, 1989; Slifkin \& Doyle, 1990; Doyle \& Slifkin, 1994; Jacobson \& Doyle, 1996).

The term lectin came from latin verb "legere " and reflects an ability of particular proteins (hemagglutinins) to aggregate different kinds of RBCs (Boyd \& Shapleigh, 1954). Several authors have tried to improve the original definition to make it more exact, in terms of modern knowledge on the structural and functional properties of the lectin molecules and their sugar binding sites (Goldstein et al., 1980; Kocourek \& Hořejší, 1981; Barondes, 1988; Drickamer, 1988; Yoshizaki, 1990; Lee, 1992). Most recently, according to Peumans (1995), lectins are proteins or glycoproteins carrying at least one binding site, possessing a reversible specific interaction with the particular carbohydrate moiety. The author has distinguished three subgroups 
of lectins: merolectins having only a binding site for a carbohydrate, hololectins with two or more homologous binding sites for saccharides, and chimerolectins carrying binding sites for different sugar moieties, and having an enzyme activity as well. The last mentioned subgroup used to be called lectinoids (Gilboa-Garber \& Garber, 1989). To combine different binding activities in such molecules seems to be a fairly effective way to make regulatory tools for mechanisms of recognition and molecular identification by the receptor/co-receptor systems. In contrast, proteins having an enzyme activity for the carbohydrate substrates, regulatory proteins (e.g. repressor in the lac operon), or antibodies with idiotypic specificity to saccharides/glycoconjugates are not considered as lectins (Kocourek \& Hořejší, 1981).

Other molecules with carbohydrate binding domain, which likely do not fall in the lectin family, are above mentioned scavenger receptors (Pearson, 1996). They occur also on the surface of hemocytes carrying a binding specificity to anionic polysaccharides (e.g. fucoidan, dextran sulfate, chondroitin sulfate). Scavenger proteins as well as the proteins with a binding affinity for oligo/polynucleotides seem to play a significant role in the receptor functions over the whole evolution of innate immunity. Together with both lipopolysaccharide (LPS)- and glucan-binding proteins they constitute an important group of molecules engaged in non-self recognition in invertebrates.

Drickamer (1988) defined lectins as both soluble and/or membrane bound proteins, post-translationally modified providing often multimolecular complexes built from a number of identical subunits. The author has structurally discriminated two major types of lectins: S-type with thiol dependent activity localized in both intra-/extracellular compartments and $\mathbf{C}$-type with $\mathrm{Ca}^{2+}$ dependent activity in extracellular space. The C-type lectins are more variable in structure and more specific to organs and tissues. However, their sequence data revealed a common and homologous region responsible for binding of carbohydrates, the carbohydrate region domain (CRD) (Lee, 1992). An important subtype of C-lectins is called collectins. They have a collagen domain, a neck region and a globular C-type lectin-binding domain (Epstein et al., 1996; Ezekowitz et al., 1996).

\section{LECTINS IN ARTHROPODS}

AND VECTOR-PATHOGEN SYSTEMS

Lectins are in the focus of glycobiology research:

- as effector, receptor, and regulatory molecules in the processes of self/non-self recognition and innate immunity, cell adhesion, tissue differentiation, and in the glycoprotein (glycoconjugates) metabolism;
- as a tool for the analyses of glycans, structural mapping of glycosylation products, characterization and affinity separation of cells, histochemical and ultrastructural analyses of glycokalix, induction of functional activities of the cells (mitosis), etc.

The interest of scientists and the number of papers devoted to lectins have increased tremendously within last decade particularly with respect to a lectin function in animals including insect and other arthropods (for review e.g. Olafsen, 1986, 1996; Ratcliffe \& Rowley, 1987; Pathak, 1993; Natori, 1994). The main attention has been paid to arthropod lectins as molecules employed in innate immunity or in immune reactions based on recognition of self/non-self (for review e.g. Cohen, 1984; Dunn, 1986; Komano, 1991; Šíma \& Větvička, 1990; Karp, 1996).

Blood-sucking arthropods provide a good opportunity to investigate and discuss structural and functional aspects of the lectins and protein-carbohydrate interactions taking place in the mechanisms of pathogen/ parasite transmission (for review Ingram \& Molyneux, 1991). The first milestone paper on tissue specific lectins of a vector was published on the kissing bug Rhodnius prolixus by Pereira et al. (1981). However, most results on vector lectins have come from research on tsetse flies and have shown that tissue specific lectins might play the crucial role in control of tsetse fly infection by African trypanosomes (for review Maudlin \& Welburne, 1988; Maudlin, 1991).

The most comprehensive review summarizing the knowledge of tissue-specific lectins in blood-sucking insects was published by Ingram \& Molyneux (1991). Following physiological functions of arthropod lectins and their interactions with transmitted pathogens were described:

- regulation of differentiation processes and morphogenesis (e.g. growth factors, cell adhesion) (Yoshizaki, 1990; Natori \& Kubo, 1996);

- recognition of self/non-self in immune and defence reactions (opsonins, encapsulation, phagocytosis, homing factors) (Vasta \& Marchalonis, 1983; Lackie \& Vasta, 1988; Vasta, 1991; Olafsen, 1996);

- control of tissue distribution of endosymbiotic microorganisms (Jomori et al., 1990);

- refractoriness/susceptibility (regulatory role of vector infections by transmitted pathogen/parasite, killing factors) (Maudlin \& Welburn, 1987; Welburn et al., 1989; Welburn \& Maudlin, 1993; Yoshino \& Vasta, 1996); - differentiation factors of a vector-specific developmental stage of the parasite/pathogen (e.g. signalling factors of parasite maturation) (Welburn \& Maudlin, 1989, 1993).

Protein (lectin)-carbohydrate interactions are one of those which participate in molecular ecology of the vector-pathogen/parasite relationships. Tissue specific 
lectins of blood sucking arthropods interact with glycosylated molecules of receptors on the surfaces of pathogens or their cells within appropriate developmental stages and vice versa. For instance, bacteria or other intracellular parasites have often employed their surface lectins to enter into phagocytes by the mechanism of lectinophagocytosis (Ofek \& Sharon, 1988). Reciprocal lectin-carbohydrate interactions in vector pathogen/parasite systems are shown in Figure 1.

\begin{tabular}{|c|c|}
\hline $\begin{array}{l}\text { INNER ENVIRONMENT } \\
\text { of VECTOR } \\
\text { (blood-sucking arthropods) }\end{array}$ & $\begin{array}{l}\text { PATHOGEN (PARASITE) } \\
\text { (viruses, bacteria, } \\
\text { protozoa, helminths) }\end{array}$ \\
\hline $\begin{array}{r}\text { ENDOGENOUS LECTINS } \\
\text { (AGGLUTININS) } \\
\text { /tissue specific/ }\end{array}$ & $\begin{array}{l}\text { CARBOHYDRATES } \\
\text { of the structural } \\
\text { GLYCOCONJUGATES } \\
\text { (developmental stage- } \\
\text { specific receptors) }\end{array}$ \\
\hline $\begin{array}{r}\text { CARBOHYDRATES } \\
\text { of the structural } \\
\text { GLYCOCONJUGATES }\end{array}$ & $\begin{array}{l}\text { LECTINS/LECTINOIDS } \\
\text { (factors of virulence, } \\
\text { developmental } \\
\text { stage-specific) }\end{array}$ \\
\hline
\end{tabular}

Fig. 1. - Reciprocal lectin-carbohydrate interactions in vector-parasite systems.

Expression of genes coding for these molecules as well as regulatory mechanisms of their expression is left to be answered. The inducibility of insect lectins to various stimuli is known mainly from the hemolymph; some of them are induced by viruses, bacteria or eucaryotic parasites (Ingram et al., 1984; Smail \& Ham, 1988; Minnick, 1986; Mori et al., 1989). An inducibility of hemolymph lectin activity was recorded in Bombyx mori larvea after treatment with 20-hydroxyecdysone (Amanai et al., 1991). The gut lectin activities of several vectors were induced after a blood meal as shown below.

The review is mainly focused on lectins or lectin-like molecules of the digestive tracts of selected groups of blood-sucking arthropods. Digestion of these animals differs from one to other in histology, ultrastructure and physiology as well (Chapman, 1985; Billingsley, 1990; Peters, 1992; Kingsolver \& Daniel, 1995; Romoser, 1996).Very little is known about the specific site where the gut lectins of arthropods are synthetized, and how they are distributed (Vasta, 1992). Although the site of synthesis of such molecules has been suggested in some studies (Peters et al., 1983; Hypša \& Grubhoffer, 1995; Palánová \& Volf, 1997), location of specific mRNA by hybridization in situ is the only prove of the lectin origin in the tissue/cell.

The main goal of this paper is to summarize and generalize recent knowledge on lectins and lectin-like molecules in the digestive tissue (gut) of vectors. The survey is focused on five selected groups/representatives of disease vectors which have also been under investigation by the authors: ticks, kissing bugs, mosquitoes, sandflies, and tsetse flies.

\section{SPECIFIC PART}

TiCKS (PARASITIFORMES: IXODOIDEA)

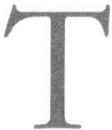
icks as hematophagous parasites represent an important group of the vectors of viral, bacterial and protozoan causative agents of diseases. The first lectin studies were done on the hemolymph of the soft ticks: Ornithodoros tartakouskyi, O. papillipes and Argas polonicus (Vereš \& Grubhoffer, 1990; Grubhoffer et al., 1990; Grubhoffer \& Mat'ha, 1991). Kamwendo et al. (1993) reported hemagglutinating activities in the hemolymph, gut homogentes, and salivary glands in the tick Rhipicephalus appendiculatus, the field vector of East Coast fever which is a tickborne disease of cattle, caused by the protozoan parasite Theileria parva. Human and rabbit, but not bovine, RBCs did show significantly higher values of hemagglutination titres in tissue samples coming from the fed ticks than the unfed ones. The highest increase was recorded in the gut extract. Kamwendo et al. (1995) studied a role of the tick salivary gland hemagglutinin of the tick $R$. appendiculatus in terms of a mechanism of the protozoan parasite T. parva transmission. A significant increase was observed in T. parva acinar infection rates in the salivary glands of $R$. appendiculatus fed on ears of rabbits infused with melibiose and raffinose (hemagglutination inhibiting sugars). In contrast, mannose and turanose (non-inhibitory sugars) did not cause an elevation of T. parva acinar infection rates at all.

The sheep tick Ixodes ricinus, transmitting tick borne encephalitis (TBE) virus and spirochete Borrelia burgdorferi sensu lato/stricto, seems to be the most important tick vector in Europe. Midgut hemagglutinating activity of $I$. ricinus has been found and partially characterized by Uhlír et al. (1996). Native mouse erythrocytes were the most sensitive detection cell system in a wide $\mathrm{pH}$ range of 6.5-8.0. Binding specificity analysis has shown simple sugars N-acetyl-D-galactosamine, N-acetyl-D-glucosamine, rhamnose, dulcit and glycoconjugates fetuin, hyaluronic acid, laminarin (beta 1,3-glucan) and bacterial LPS as molecules with strong inhibitory effect in hemagglutination assay. Midgut extracts from unfed ticks lack a hemagglutinating activity. Mouse polyclonal antibodies raised toward midgut hemagglutinating activity were discriminated on western blot, four protein molecules of 37, 60, 65, and $73 \mathrm{kDa}$ as putative structural components of the 
lectin(s) or the whole hemagglutinating complex, respectively (Uhlír et al., 1996). Whereas the components of 37 and $60 \mathrm{kDa}$ are glycoproteins modified by both high mannose and complex types of N-glycans, the $70 \mathrm{kDa}$ subunit has likely only complex type of glycans (Uhlír et al., 1994). Using the specific mouse polyclonal antibodies the midgut hemagglutinin (hemagglutinating activity) has been immunohistologically localized only in the midgut cells, and not in the gut content or other tick tissues including hemolymph (Uhlír et al., 1996).

Agglutinins found in hemolymph/hemocytes and in salivary gland extract of the adult $I$. ricinus ticks apparently differ from midgut agglutinin. They are sialic acid-binding proteins with stuctural subunits of $85 \mathrm{kDa}$ and $70 \mathrm{kDa}$ respectively (Grubhoffer et al., 1991; Grubhoffer et al., 1994; Grubhoffer \& Durnová, 1996). Hemolymph/hemocyte agglutinin was detected in the granules of both types of granular hemocytes, the membrane of hemocytes, the basal laminae surrounding the hemocoel, cells attached to the midgut, invaginations of Géné's organ, and granular inclusions of nephrocytes (Kuhn et al., 1996).

Binding characteristics of the tick midgut agglutinin are consistant with LPS-binding agglutinins in the gut tissue of other blood-sucking arthropods. It seems that the midgut agglutinin as a potential LPS-binding protein (LPS-BP) could (in co-operation with digestive enzymes) affect gram-negative spirochetes B. burgdorferi going through gut epithelium. On the other hand, sialic acid-binding lectins from hemolymph and salivary glands might be able to bind borrelia cells by interactions with sialic acid in the wall of spirochetes (Hulínská et al., 1992) or with LPS via 2-deoxy-3ketooctonic acid, a structural part of the LPS molecule which is sterically similar to sialic acid (Vasta \& Marchalonis, 1984).

Factors taking place in processes of pathogen/parasite transmission by the tick are reviewed by Friedhoff (1990). According to this author, the midgut agglutinin/ LPS-BP might fall among factors associated with development of pathogen/parasites in the digestive tract of the tick vector. The process of blood digestion in ticks differs from that of hematophagous insect, where protein digestion proceeds rapidly and takes place in the lumen of the gut (Gooding, 1972). The digestion in ticks is intracellular (Balashov, 1972). It proceeds slowly, and the $\mathrm{pH}$ optimum of proteases is about 3.0, while the $\mathrm{pH}$ of the gut content is 6.5 (Akov et al., 1976). In hard ticks, the blood meal is taken up by the digestive cells by means of fluid-phase endocytosis and via receptor-mediated endocytosis. Large particles such as whole cells are phagocytized. The binding activity of the midgut agglutinin/LPS-BP is $\mathrm{pH}$ dependent. At $\mathrm{pH} 3.0$ which is an optimum value for the gut pro- teases, the midgut agglutinin does not work at all whereas at $\mathrm{pH} 6.5$ a hemagglutinating activity of this binding protein reaches its optimum (Uhlír et al., 1996).

\section{Kissing Bugs (Heteroptera: Reduviddae)}

Hematophagous bugs of the subfamily Triatominae play an important role as the vectors of Trypanosoma cruzi, the causative agent of Chagas's disease. Although many triatomine species are capable of the disease transmission, most of the knowledge on the vectorparasite interactions and the possible role of lectins and lectin-like activities has been derived from few model species, mostly Rhodnius prolixus and Triatoma infestans. In the course of these studies, several hemagglutin activities have been detected in various tissues such as hemolymph, salivary glands, crop and midgut (Pereira et al., 1981; Barraco \& Loch, 1988; Gomes et al., 1988; Gomes et al., 1991; Gregorio \& Ratcliffe, 1991; Hypša \& Grubhoffer, 1995) and the possible significance of these compounds for T. cruzi development has been suggested. Since T. cruzi does not invade the host hemocoel and its complete development takes place in gut lumen, the gut agglutinins may be of particular importance in respect of the development of this parasite.

The investigation of triatomine tissue lectins and their role in host-parasite interactions began with the classical study by Pereira and co-workers (Pereira et al., 1981) who observed a hemagglutination activity against rabbit erythrocytes in hemolymph, midgut and crop of Rhodnius prolixus. They demonstrated that the agglutinins from individual tissues represented distinct lectins differring in their binding specificities. Thus, the crop agglutinin displayed a pronounced specificity to $\mathrm{N}$-acetyl-D-mannosamine and LPS from Salmonella weslaco containing this sugar, while the same compounds were unable to inhibit the midgut lectin, the latter being inhibited by $\mathrm{N}$-acetyl-D-galactosamine and linked derivates of this sugar. The agglutination with T. cruzi epimastigotes showed that midgut, but not crop lectin could agglutinate untreated epimastigotes. Further, and more importantly, agglutination assay with various kinetoplastids revealed that the binding capacity of the gut lectin was species- and even stagespecific. While epimastigotes of T. cruzi were efficiently agglutinated, no agglutination was obsered with trypomastigotes of the same species nor with some other protozoans which are not natural inhabitants of the bugs. Such pronounced binding specificity suggests that it may reflect a particular adaptive trail of host or parasite rather than an accidental side effect. These observations lead the authors to the suggestion of possible biological significance of lectin-parasite interactions. This idea was strongly supported by the fact that stage-specific lectin receptors had been deter- 
mined in trypanosoms using cytochemistry methods (Alves \& Colli, 1974; Souza \& Meyer, 1975; Pereira et al., 1980).

In $T$. infestans, the $20 \mathrm{kDa}$ polypeptide with high hemagglutination activity has been described from crop (Hypša \& Grubhoffer, 1995). Unlike the R. prolixus lectin, this agglutinin could not be inhibited by any of the 20 tested mono or oligosaccharides. However, it displayed a strong affinity to some bacterial LPS. Assays using mutants lacking particular parts of the LPS molecule showed that the binding site was indeed directed towards the sugar moiety of the LPS molecule. This finding suggests that the hemagglutinin possesses a complex binding site recognizing a particular fragment of a sugar chain rather than individual monosaccharide residue and therefore does not fit to the conventional lectin definition. Using specific polyclonal antibodies, it was demonstrated that the agglutinin is most probably synthesized in the cells of the gut wall and released into the gut lumen. Similarly as in the study on $R$. prolixus agglutinins (Pereira et al., 1981), no differences in the agglutinin activity were observed between starved and fed bugs. This fact contrasts strikingly with the situation in bloodsucking Diptera where the gut lectin activity seems to be induced by bloodmeal (see below). It is pertinent to mention here that the presence of molecules similar to LPS has been demonstarted in extracts of T. cruzi (Ketteridge, 1978) and the surface location of this molecule has been subsequently determined (Goldeberg et al., 1983). Also, the gut of triatomine bugs is inhabited by symbiotic bacteria (Wiggesworth, 1936). Although they are Gram-positive bacteria and do not have LPS, they carry polysaccharides on their surface which might interact with gut agglutinins.

In addition to the general ability of some triatomine lectins to agglutinate T. cruzi epimastigotes, an actual effect of $T$. infestans tissue homogenate upon the growth and development of $T$. cruzi has been reported by Isola and co-workers (Isola et al., 1981, 1986a, b). In a series of experiments, the authors demonstrated that in vitro differentiation of $T$. cruzi epimastigotes into infective metacyclic forms can be enhanced by T. infestans gut homogenate obtained from the bugs 24 to 48 hours after bloodmeal. The loss of the morphogenetic effect after epimastigotes treatment with trypsin and the subsequent recovery after incubation in medium suggested that the interaction was dependent on the surface membrane receptors. However, it seems unlikely that any of gut lectins described above correspond to the differentiation factor; the differentiation activity was induced after bloodmeal and disappered after three weeks of starvation (Isola et al., 1981), while no significant differences in hemagglutination activity were found between starved and fed bugs (Pereira et al., 1981; Hypša \& Grubhoffer, 1995). The attempts to identify the differentiation factor(s) indicate that $\alpha^{\mathrm{D}}$ globin derived from the bloodmeal may be at least partially responsible for the epimastigotes differentiation (Garcia et al., 1995).

The effort to make any generalizations on the nature of gut agglutinins and their effect on trypanosomes has been hampered by small number of experiments done so far and a considerable variance in the results. Gregorio \& Ratcliffe (1991) analysing agglutinins of two triatomine species, $R$. prolixus and $T$. infestans, failed to detect the hemagglutination activity in $R$. prolixus from tissues other than hemolymph. On the other hand, high agglutination activity was detected in crop and midgut of $T$. infestans suggesting that the absence of $R$. prolixus gut agglutinin may not be explained as a mere consequence of unappropriate experimental design. This observation is hard to interpret since the gut agglutination activity has been later confirmed in R. prolixus (Ratcliffe et al., 1996). Pereira et al. (1981) identified several monosaccharides as a potent inhibitors of $R$. prolixus gut lectin while Ratcliffe et al. (1996), using the same species, could not find any monosaccharide inhibitor of gut agglutinins. The latter result is, however, in concordance with the situation in T. infestans where no sugar inhibitors were found against the agglutination activity of gut extract (Gregorio \& Ratcliffe, 1991; Hypša \& Grubhoffer, 1995), while some glycosylated proteins and bacterial lipopolysaccharides proved to be potent inhibitors. Since the molecular weight of the gut agglutinins reported by Pereira et al. (1981) and Gregorio \& Ratliffe (1991) has not been determined, it is difficult to hypothesize on their relation to the LPS binding protein.

Although it is quite possible that various experimental conditions, such as the buffers used or the source of the blood fed to bugs, may produce the differences in results, it becomes clear that at least some of the controversies are due to the variability among the host or parasite strains used in experiments. Using three different strains of T. cruzi, Mello et al. (1996) clearly demonstrated strain variability in the ability to establish the infection. In addition, they showed, that in each case the infectivity was positively correlated with crop agglutinin titre and negatively correlated with the titre of the crop lysin. Similarly, they observed the negative correlation between the survival of trypanosome in host haemocoel and their agglutination by haemolyph. These observations indicate that the lectin/carbohydrate interactions between triatomine bugs and T. cruzi may be at least partially responsible for parasite infectivity and development. 


\section{Mosquitoes (Diptera: Culicidae)}

Mosquitoes transmit malaria, filariases and they are the most important vectors of arboviruses. For a long time, the only evidence about the mosquito lectins had come from the study of Eaton et al. (1978). They have shown that the hemagglutinating activity of nonarbovirus-infected Aedes albopictus larval cell culture fluids could be inhibited by mannosyl moieties. More recently, Ham et al. (1991), working with two strains of the mosquito Aedes aegypti differing in susceptibility to Brugia pahangi, reported endogenous carbohydrate binding proteins in the gut and peritrophic matrix. Addition of N-acetyl-D-glucosamine, a sugar present on the microfilarial sheath, significantly increased the migration rate of microfilaria. This enhancement was greater for the refractory strain of $A$. aegypti. It was postulated that the above mentioned sugar was acting by blocking gut/peritrophic matrix carbohydrate binding proteins (lectins) which would normally inhibit microfilariae migration. Evidence for the role of the hemolymph lectin in vector-parasite interactions comes from the work of Kobayashi \& Yamamoto (1993) and Kobayashi et al. (1994). Two pathways of defence responses (melanization and hemolysis) of the mosquito Armigeres subalbatus against invasion by filaria Brugia malayi is mediated by the lectin activity.

In Anopheles gambiae, lectin activities in hemolymph and gut extracts were demonstrated by Molyneux and collaborators (Mohamed et al., 1992). No apparent differences in hemagglutinin titres were detected between male and female mosquitoes. Agglutinin activities were not increased following a bloodmeal. Analyses of the binding specificities revealed the presence of multiple (hetero-) agglutinins specific for glucose based disaccharides, glucose linkages with fructose and to a lesser extend, for D-glucosamin, N-acetyl-D-glucosamine, galactose and its deoxy derivatives (Mohamed et al., 1992). They were thermo-labile glycoproteins, affected by freezing and thawing treatments, and contained disulphide and hydrogen bonds. Activity was $\mathrm{Ca}^{2+}$, to a lesser extent $\mathrm{Mg}^{2+}$ ion, dependent with optimum at slightly acid or neutral $\mathrm{pH}$. The subunit of midgut extract agglutinin had a molecular size of $65 \mathrm{kDa}$ whilst that of hemolymph agglutinin was $40 \mathrm{kDa}$ (Mohamed \& Ingram, 1994).

Nayar \& Sehdal (1993) investigated a hemagglutination activity in tissue extracts of salivary glands, midgut and thoratic muscle including that in the hemolymph (both cell free and with hemocytes) of uninfected strains $A n$. quadrimaculatus and Ae. aegypti susceptible and refractory to Brugia malayi parasite. High activity with sugar binding specificity for lactose, sorbose, xylose, $\mathrm{N}$-acetylneuraminic acid, and partially also for $\mathrm{N}$-acetylD-galactosamine and N-acetyl-D-glucosamine was found in salivary glands of An. quadrimaculatus strains but not in any of the tissues of Ae. aegypti strains.

Contrary to above mentioned results, Grubhoffer \& Wells (1993) and Grubhoffer \& Noriega (1995) found and partially characterized an agglutinin/lectin in the midgut extract of the mosquito Ae. aegypti (Rockefeller strain).The highest hemagglutination activity was observed in female midgut extracts using native rabbit RBCs in the hemagglutination assay. Activity showed binding affinity to D-hexosamines, glucuronic acid and several glycoconjugates, including bacterial LPSs and strongly bound sialylated glycoproteins. Agglutinin likely falls to C-typ lectins. It is dependent on $\mathrm{Ca}^{2+}$ ions (not $\mathrm{Mg}^{2+}$ or $\mathrm{Mn}^{2+}$ ), with $\mathrm{pH}$ optimum in a range of 7.0-7.6. The lectin purified by a combination of both a ion-exchange affinity and hydrophobic chromatography was a protein of $57 \mathrm{kDa}$ (Grubhoffer, unpublished results).

The midgut lectin activity of $A$. aegypti is strongly induced by blood or protein meal. Part of the inducible lectin activity seems to be associated with the peritrophic matrix. The patterns of carbohydrate binding specificity of hemagglutination activity before and after feeding are identical (Grubhoffer \& Wells, 1993). We assume that the process of lectin inducibility is closely related to the induction and functional activity of either early or late midgut trypsin. Regulatory principles steering syntesis of both early and late trypsins in the mosquito midgut have been investigated (Graf \& Briegel, 1989; Noriega et al., 1994; Barrilas-Mury et al., 1995) but it left to be solved how a lectin inducibility relates to mechanisms of induction of the trypsins at the level of the gene expressions. The time course of hemagglutinating activity of the midgut lectin almost follows the midgut trypsin activity, however, the increase of lectin activity within the first 5 hours after a protein meal is quicker (Grubhoffer \& Wells, 1993).

In spite of a structural difference of the molecules carrying both distinguished activities we do suggest an effective cooperation of functional activities of the midgut lectin and trypsins/gut proteases during pathogen/parasite transmission. A mechanism of how the mosquito midgut trypsin is engaged in pathogen transmission has been reported by Ludwig et al., 1991 on model experiments with LaCross virus vectored by the mosquito Ae triseriatus. The former G1 glycoprotein of LaCross virus is cleaved by the midgut trypsin to reveal hydrophobic sequences which would fuse with the plasma membrane of the midgut-epithelial cells, and the midgut lectin might function as soluble or bound receptor molecules for $\mathrm{G} 2$, the latter envelope glycoproteins of the LaCross virion. 


\section{SANDFlies (DipTERA: Psychodidae)}

Sandflies of genera Phlebotomus and Lutzomyia are vectors of various species of Leishmania. Sandfly lectins agglutinating human RBCs and Leishmania promastigotes were firstly reported by Wallbanks et al. (1986) in lysates of heads, midguts and hindguts of Pblebotomus papatasi. Ingram \& Molyneux (1991) extended this study comparing agglutination activity of three Phlebotomus species ( $P$. papatasi, P. perniciosus and $P$. perfiliewi) against human and $\operatorname{dog} \mathrm{RBC}$ and against promastigotes of various Leishmania infantum strains; both RBC and Leishmania promastigotes were used untreated or treated with a number of enzymes. More recently gut hemagglutination and parasite-agglutination activities were reported in other sandfly colonies including those of Lutzomyia species (Volf, 1993; Volf et al., 1994).

Sandfly gut lectins differed according to sex and physiological state of the fly. Hemagglutinin titres were higher in females compared to male flies with similar finding for parasite-agglutination activity (Wallbanks et al., 1986). Differences between males and females were highly significant, activity of unfed females was about 100 times higher than that of males (Volf \& Killick-Kendrick, 1996). This finding suggests a possible role for lectins in blood digestion as well as in Leishmania-sandfly relationships as only female flies take a blood and transmit Leishmania parasites. Lectin was heat-labile, partially sensitive to dithiothreitol treatment, with the peak of activity at pH 7.0-8.0 (Palánová \& Volf, 1997). In two species, Lutzomyia longipalpis and Phlebotomus duboscqi, lectin activities were isolated using HPLC and characterized by SDS PAGE and immunoblotting. Anti-lectin antibodies raised in rabbit recognized mainly protein bands of $60 \mathrm{kDa}$ in $L u$. longipalpis and of $70 \mathrm{kDa}$ in P. duboscqi (Volf et al., 1995). High lectin levels were found in abdominal as well as the thoracic part of the midgut but not in the hindgut (Volf \& Killick-Kendrick, 1996).

Sandfly lectins, however, are not confined to midgut only (Wallbanks et al., 1986; Ingram \& Molyneux, 1991). Activity with same binding specifity was detected in ovaries, haemolymph, head and body lysates (Palánová \& Volf, 1997). Wallbanks et al. (1986), who reported the first finding of lectin in $P$. papatasi head lysates, expected that this activity is connected with foregut. From recent experiments it seems more likely that activity in head lysates originates from the hemolymph.

In unfed females the lectin was associated mainly with microvillar surface of midgut epithelium and was present also free in the midgut lumen. In fed ones the gut activity was elevated and the lectin was secreted into the midgut lumen and passes through the peritrophic matrix into the peritrophic space. Activity dynamics were apparently correlated with the speed of digestion in each particular species, generally it reached peak titres two days after blood meal and then went down to the base level or less immediately after defecation (Volf \& Killick-Kendrick, 1996). The magnitude of the activity response differed according to species, ranging from two fold in $\mathrm{Lu}$. carmelinoi up to sixteen fold in P. duboscqi and such differences in lectin response may influence the sandflies ability to support the development of various Leishmania species. Similar sugar-binding specificities found in unfed and fed females led to conclusion that the same lectin molecule is present, in different levels, in unfed as well fed flies (Palánová \& Volf, 1997).

Lectin secretion into the midgut lumen is triggered by proteins present in the meal. In flies fed on different protein solutions and blood derivates the hemagglutination titres increased proportionally to the protein content in the ingested meal. Both bovine serum albumine and hemoglobin solutions had equal stimulatory effect as diluted serum and RBCs suspension of the same protein content (Volf \& Palánová, 1996).

Marked differences were found in the agglutination of promastigotes of various Leishmania species/strains and high parasite agglutination titres were observed in some natural vector-parasite combinations (Wallbanks et al., 1986; Ingram \& Molyneux, 1991; Svobodová et al., 1996). Species with high hemagglutination titres usually gave high parasite agglutination titres. Intraspecific variability, in agglutination of Le. major strains by sandfly lysates was related to varying virulence of the strains to the laboratory mice (Svobodová et al., 1996). In all studies, trypanosomatids related to Leishmania spp., for example Leptomonas hertigi, Trypanosoma brucei and Crithidia fasciculata, were not agglutinated.

Various sugars were reported to inhibit hemagglutination and parasite agglutination of sandfly midgut lysates in vitro. Using human $\mathrm{O} \mathrm{Rh}+\mathrm{RBCs}$ and $P$. papatasi lysates Wallbanks et al. (1986) found two sugars, trehalose and turanose, caused marked inhibition. Ingram and coworkers reported glucose-containing sugars and aminosugars as the best inhibitors of $P$. papatasi and $P$. perniciosus hemagglutination (Ingram \& Molyneux, 1991) while both glucosyl and galactosyl derivates as inhibitors of hemagglutination of P. perfiliewi (Dr. G. A. Ingram, personal communication). In contrast, when rabbit RBCs were used as the detection system, the hemagglutination activity of all species studied was specific for galactosamine with extension to other hexosamines and some glycoconjugates, mainly heparin, fetuin and LPS of E. coli (Volf, 1993; Volf et al., 1994; Palánová \& Volf, 1997). In comparison, anti-Le. infantum activity of P. papatasi and $P$. perniciosus were specific mainly for glucosyl deri- 
vates (Ingram \& Molyneux, 1991) while these of P. perfiliewi for both glucosyl and galactosyl derivates as well for amino and N-acetylated sugars (Dr. G. A. Ingram, personal communication). Agglutination of $L e$. major and Le. donovani promastigotes by gut extracts of P. papatasi and Lu. longipalpis were inhibited mainly by mannosamine, galactosamine and N-acetyl-glucosamine (Svobodová et al., 1996).

Lipophosphoglycan (LPG), the major surface glycoconjugate of Leishmania promastigotes, was shown as a powerfull inhibitor of sandfly gut lectin. Both crude procyclic and purified metacyclic LPG of Le. major had a very strong inhibitory effect on gut hemagglutination of P. papatasi (Palánová \& Volf, 1997). During metacyclogenesis of promastigotes the LPG undergoes extensive modifications. In L. major these changes include down regulation in the number of side chains expressing terminal $B$-linked galactose in favour of those terminating with arabinose (McConville et al., 1992). This process is responsible for the control of stage-specific adhesion of promastigotes to sandfly microvilli (Pimenta et al., 1992, 1994). Recent experiments suggest that membrane-bound lectin-like receptor play a role in this process and that in P.papatas $i$ this receptor is specific for galactose-containing oligosaccharides derived from terminal parts of L. major LPG (Dr. R. Lane, personal communication).

We suppose that both molecules, secreted lectin and membrane-bound lectin-like receptor play an important role in vector-parasite interaction. Lectin-like receptor on sandfly microvilli might enable attachment of promastigotes to sandfly midgut epithelium while secreted gut lectin may inhibit Leishmania development in sandfly midgut. Addition of carbohydrate inhibitor, galactosamine, into P. duboscqi infective feed significantly increased susceptibility to infections of $L e$. major. Addition of noninhibitory carbohydrate, galactose, did not cause such effect (Volf et al., 1997), infective rates and intensity of infection were the same as in group without any sugar (Čiháková \& Volf, 1997). However, we can not exclude the possibility that secreted lectin affects parasite development indirectly through the digestion process of the vector; addition of galactosamine into the bloodmeal caused drastic changes in sandfly digestion (Volf et al., unpublished). Agglutinin found on Leishmania surface (Schottelius, 1992; Svobodová et al., 1997, a) is not likely to be involved in this attachment. The activity was lower in log-phase promastigotes which display an inherent capacity to attach to midgut microvilli than in metacyclics (Svobodová et al., 1997, a) which are not longer able to attach. Recently it was shown that Leishmania lectin play a role in the host part of the parasite-life cycle; it participates in adhesion of amastigotes and promastigotes to human phagocytic cells (Svobodová et al., 1997, b). Nevertheless, it is known that sandflies feed on plant sap which contain both sugars and lectins and this may affect development of Leishmania parasites and their transmission to vertebrate host (Schlein \& Jacobson, 1994).

\section{TSETSE FliEs (DipTERA: GlOSSINIDAE)}

Tsetse flies of genus Glossina are vectors of Trypanosoma flagellates, causative agents of African trypanosomiases. Until now, Glossina m. morsitans has been the most investigated model species which enables to form a hypothesis about lectins as the molecular factors responsible for an interaction of trypanosoma with tissue specific receptors in tsetse.

Studies of lectins was preceeded by an ultrastructural analysis of the functional-morphological aspects of an attachment of different trypanosoma species to an apropriate part of the tsetse gut (Vickerman, 1973; Molyneux, 1977). The first record of tsetse haemolymph and gut lectins with hemagglutinating and parasite agglutinating properties was published by Ibrahim et al. (1984). The activity in midgut and hindgut of G. austeni agglutinated procyclic forms of Trypanosoma brucei and was specific for D-glucosamine.

The evidence about the role of lectins in trypanosoma/tsetse interaction came from experiments of Maudlin \& Welburn (1987) and Welburn et al. (1989) who showed that exposure of trypanosomes to secreted lectin in tsetse midgut can result in trypanosome death. Electron micrographs of midguts of G. $m$. morsitans suggest that procyclic trypanosome damage were caused by lectin action. Welburn et al. (1994) suggested that the midgut lectin is responsible for the agglutination of trypanosomes in the fly midgut by binding to the procyclic surface coat, prior to their establishment in the ecto-peritrophic space (Welburn et al., 1994). Feeding glucosamine or $\mathrm{N}$-acetylglucosamine to G. morsitans significantly increases the number of flies which develop trypanosome midgut infections. D-glucosamine inhibits the killing of procyclic trypanosomes taken as an infective feed.

In $G$. palpalis the midgut infection rates of T. congolense was also potentiated by the addition of glucosamine to the infective meal, but not to the extent seen in G. morsitans. Glossina palpalis has, in contrast to G. morsitans, two trypanocidal gut molecules which accounts for the innate refractoriness of this species: the glucosamine-specific lectin and another activity inhibited by galactose (Welburn \& Maudlin, 1993). Two different lectin systems were found also in the midgut of G. tachinoides, another species of G. palpalis group. Structural components of 26 and $29 \mathrm{kDa}$ were distinguished by monospecific rabbit and mouse antisera and by slightly different binding specificities 
in term of both qualitative and quantitative features (Grubhoffer et al., 1994).

Tsetse midgut lectins are produced in response to the bloodmeal. Teneral or starved G. palpalis showed little activity (Welburn et al., 1989) while in blood-fed the trypanoagglutinins became elevated to peak titres 2-3 days after a bloodmeal and fall to initial levels five days later (Stiles et al., 1990). Similarly in five other Glossina species, midgut lectin activities after engorgement and follow the similar cyclical pattern of secretion (Volf et al., 1992; Grubhoffer et al., 1994). This change in lectin activities is thought to be responsible for differences in susceptibility of teneral and nonteneral flies. Flies fed before an infective feed were able to remove trypanosomes from their midguts more quickly than flies infected as tenerals (Welburn \& Maudlin, 1989). Feeding flies before infection also abolished the differences in rate of trypanosome killing found between teneral "susceptible " and "refractory " $G$. m. morsitans, suggesting that maternally inherited susceptibility to trypanosome infection is a phenomenon limited to teneral flies (Welburn \& Maudlin, 1992). Results of Lehane \& Msangi (1991) who described an strong increase of of the lectin activity in old starved tsetse flies seem to be inconsistant with above mentioned experience.

However, lectins also provide a signal for trypanosome maturation. This process was reported by Welburn \& Maudlin (1989) for T. congolense in G. morsitans. The duration of lectin signal required to induce maturation was determined by the sequential addition or removal of a specific inhibitor, the $\mathrm{D}+$ glucosamine to the diet of infected Glossina males. Midgut trypanosomes retained their ability to mature throughout their life in the fly when lectin activity in the midgut was inhibited. Once sugar inhibition was removed maturation of trypanosoma procyclic forms was able to proceed.

While the Dr. I. Maudlin's group was interested mainly in lectin function during trypanosoma infections other authors focussed more on characterization of physicochemical properties and sugar/binding specificity of lectins from various tsetse species. Ingram \& Molyneux (1988) described gut hemagglutinating activities of G. morsitans inhibited by simple sugars like D-glucose, D-galactose, D-mannose as well as their deoxy derivatives. In addition, a non-proteolytic and partially termostable hemolysin was detected in tsetse midgut samples. Stiles et al. (1990) have identified both midgut trypanoagglutinin and trypanolysin active in the posterior midguts of G. p. palpalis. The lytic substance was reported to contain two structural subunits of 10 and $12 \mathrm{kDa}$, whereas the agglutinin (lectin) only one structural unit of $67 \mathrm{kDa}$.

New insight in the role of tsetse lectins in trypanosoma development was introduced by the study of Maudlin
\& Ellis (1985). Their results from both field and laboratory-reared tsetse showed a linkage between susceptibility to trypanosome infection and presence of intracellular symbionts (rickettsial-like organisms, RLO) The relationship between RLOs and trypanosome infections in natural populations of tsetse in Africa was investigated by Maudlin et al. (1990). A population of G. p. palpalis showed strong association between trypanosome and RLO infection in spite of the fact that both infections were at low levels in this species suggesting that this particular population is highly refractory to typanosome infections. In contrast, Moloo \& Shaw (1989) published that susceptibility of the laboratory reared $G . m$. centralis to $T$. congolense infection was not associated with density of RLOs within the midgut epithelial cells. The fact that there are exceptions to the association is not surprising, susceptibility to trypanosome infection in the laboratory is not an all-or-nothing phenomenon (Maudlin, 1982). Welburn et al. (1993) proposed a model for susceptibility of tsetse to trypanosome infection based on the generation of N-acetyl-D-glucosamine by RLO endochitinase activity in tsetse pupae inhibiting midgut lectin in teneral flies. RLO from tsetse midguts showed high levels of endochitinase activity. A line of G. m. morsitans highly susceptible to midgut trypanosome infection and with high incidence of RLO infection possessed significantly greater chitinolytic activity than $G$. austeni which had low RLO incidence and were correspondingly refractory to midgut infection.

Midgut trypsin or a similar protease is another activity which seems to be involved in tsetse-trypanosoma interaction. Osir et al. (1993) and Abubakar et al. (1995) proposed midgut lectinoid in G. m. morsitans which has, besides lectin binding site with affinity for D-glucosamine, enzyme activity of the trypsin. The same group (Osir et al., 1993) isolated from midgut extracts of $G$. longipennis a blood- meal induced lectin with proteolytic activity. It was a glycoprotein composed of two noncovalently-linked subunits of 27 and $33 \mathrm{kDa}$, and similarly to G. m. morsitans its enzyme activity was strongly inhibited by D-glucosamine (Osir et al., 1993, 1995). The fact that trypsin activity of proposed lectinoid can be inhibited competitively by sugar D-glucosamine makes these results questionable.

The mechanism of recognition of trypanosomes in a tsetse fly seems to be complex process with different binding proteins and enzymes. For instance, van den Abbeele et al. (1995, 1996) recently characterized trypanosome binding proteins in glossina midgut extracts, and described that transformation of trypanosomes is mediated by activation of parasite adenylat cyclase by midgut factors of the vector. 


\section{CONCLUDING REMARKS}

$\mathrm{R}$ ecent results suggest that gut lectins of bloodsucking vectors have, besides an important role in vector-pathogen relationships, some general physiological properties.

Studies on ticks and three families of blood-sucking Diptera clearly showed that midgut lectin activities are blood-meal induced and are secreted in the response to proteins in ingested meal. Similarly, in stable fly (Stomoxys calcitrans) the midgut lectin activity is induced by blood-meal (Dr. M. Lehane, personal communication). These facts suggest that gut lectins participate in blood-meal processing and digestion. Close functional relationship and cooperation with digestive enzymes are expected in some systems.

Gut lectins of all vector groups studied have an affinity to LPS (in bloodsucking Diptera) or are LPS-BP (kissing bugs, ticks) which suggests the possible role of lectins as antibacterial agents. In sandflies this finding is supported by the fact that inhibition of lectin activity in vivo strongly increases the susceptibility of females to bacterial infections (Volf et al., unpublished). Increase of the activity after blood-feeding, in some groups, may reflect the higher risk of contamination of gut content during ingestion of the blood.

\section{REFERENCES}

Abubakar L., Osir E.O. \& Imbuga M.O. Properties of a bloodmeal-induced midgut lectin from the tsetse fly Glossina morsitans. Parasitology Research, 1995, 81, 271-275.

Akov S., SAmish M. \& Galun R. Protease activity in female Ornithodoros tholozani ticks. Acta Tropica, 1976, 33, 36-52.

Alves M.J.M. \& Colli W. Agglutination of Trypanosoma cruzi by concanavalin A. Journal of Protozoology, 1974, 21, 575-578.

Amanai K., SAKURAi S. \& Ohtaki T. Site of hemolymph lectin production and its activation in vitro by 20 -hydroxyecdysone. Archives of Insect Biochemistry and Physiology, 1991, 17, 39-51.

Azambuja P., Guamaraes J.A. \& Garcia E.S. Haemolytic factor from the crop of Rhodnius prolixus: evidence and partial characterization. Journal Insect Physiology, 1983, 29, 833 837.

BaLASHOV Y.S. Bloodsucking ticks (Ixodoidae) - vector of disease of man and animals. Miscellaneous Publications of the Entomological Society of America, 1972, 8, 161-362.

Barillas-Mury C.V., Noriega F.G. \& Wells M.A. Early trypsin activity is part of the signal tranduction system that activates transcription of the late trypsin gene in the midgut of the mosquito, Aedes aegypti. Insect Biochemistry and Molecular Biology, 1995, 25, 241-246.

BARONDES S.H. Bifunctional properties of lectins: lectins redefined. Trends in Biochemical Sciences, 1988, 12, 480-482.
BARRACO M.A. \& LOCH C.T. Naturally occurring lectin in the haemolymph of Panstrongylus megistus (Hemiptera: Reduviidae). Memoares do Instituto Oswaldo Cruz, 1988, 83, 525-527.

BillingsLey P.F. The midgut ultrastructure of hematophagous insects. Annual Reviews of Entomology, 1990, 35, 219248.

Boyd W.C. \& Shapleigh E. Specific precipitating activity of plant agglutinins (lectins). Science, 1954, 119, 419.

Brossard M. \& Rais O. Passage of hemolysins through the midgut epithelium of female Ixodes ricinus $L$. fed on rabbits infested or reinfested with ticks. Experientia, 1984, 40, 561-563.

Burgos M.H., Gutierrez L.S., Lammel E. \& De Isola E.L.D. Midgut extract rich in peritrophic membrane from Triatoma infestans induces differentiations of Triatoma cruzi. Microscopia Electronica y Biologia Celular, 1989, 13, 151166.

Chapman R.F. Structure of the digestive system. In: Comprehensive Insect Physiology, Biochemistry and Pharmacology, Vol. 4, Kerkut G.A. \& Gilbert L.I. (eds.), Pergamon Press, Oxford and New York, 1985, 165-211.

ČIHÁKOVÁ J. \& Volf P. Development of different Leishmania major strains in the vector sandflies Phlebotomus papatasi and P. duboscqi. Annals of Tropical Medicine and Parasitology, 1997, 91, 299-311.

CoHen E. (ed.) Recognition proteins, receptors and probes: invertebrates. Progress in Clinical and Biological Research, 1984, 157, 1-207.

Coon L.B., Rosel-Davies R. \& Tarnovski B.I. Bloodmeal digestion in ticks. In: Morphology, Physiology and Behavioral Biology of Ticks. Sauer J.R. \& Hair J.A. (eds.), Willey and Sons, New York, 1986, 248-279.

Doyle R.J. \& Slifkin M. (eds.) Lectin - microorganism interactions. Marcel Dekker, Inc., 1994, 1-401.

Drickamer K. Two distinct classes of carbohydrate-recognition domains in animal lectins. Journal of Biological Chemistry, 1988, 263, 9557-9560.

DunN P.E. Biochemical aspects of insect immunology. Annual Reviews of Entomology, 1986, 31, 321-339.

EATON B.T., WARD R. \& ARTSOB H. Aedes albopictus cells release a goose red blood cell agglutinin. Intervirology, 1978, 9, 362-369.

Epstein J., Eichbaum Q., Sheriff S. \& Ezekowitz B.A.R. The collections in inmate immunity. Current Opinion in Immunology, 1996, 8, 29-35.

EzeKowitz R.A.B., SASTRY K.N. \& ReID K.B.M. (eds.) Collectins and Innate Immunity. Springer-Verlag, Heidelberg, 1996, 189 p.

Franz H. The ricin story. In: Advances in Lectin Research, Vol. 1, Franz H. (ed.), Springer, 1988, 10.

FRIEDHOFF K.T. Interaction between parasite and tick vector. International Journal for Parasitology, 1990, 20, 525535.

Garcia E.S. \& DvoraK J.A. Growth and development of two Trypanosoma cruzi clones in the arthropod Dipetalogaster 
maximus. The American Society of Tropical Medicine and Hygiene, 1982, 31, 259-562.

Garcia E.S., Gonzales M.S., Azambuja P.,Baralle F.E., FraiDENRAICH D.,Torres H.N. \& Flawia M.M. Induction of Trypanosoma cruzi metacyclogenesis in the gut of the hematophagous insect vector, Rhodnius prolixus, by hemoglobin and peptides carrying D-globin sequences. Experimental Parasitology, 1995, 81, 255-261.

GilboA-Garber N. \& Garber N. Microbial lectin cofunction with lytic activities as a model for a general basic lectin role. FEMS Microbiological Reviews, 1989, 63, 211-222.

Goldberg S.S., Coprdiero M.N., Periera A.A.S. \& Mares-Guia M.L. Release of lipopolysaccharide/LPS/ from surface of Trypanosoma cruzi by EDTA. International Journal for Parasitology, 1983, 13, 11-18.

Goldstein I.J., Hughes R.C., Monsigny M., Osawa T. \& Sharon N. What should be called a lectin? Nature, 1980, 285,66 .

Gomes Y.M., Furtado A.F. \& Coelho L.B.B. Partial purification and some properties of a hemolymph lectin from Panstrongylus megistus (Hemiptera, Reduviidae). Applied Biochemistry and Biotechnology, 1991, 31, 97-107.

Gooding R.H. Digestive processes of haematophagous insects. I. A literature review. Quaestiones Entomologicae, $1972,8,5-60$

Graf R. \& Briegel H. The synthetic pathway of trypsin in the mosquito Aedes aegypti L. (Diptera: Culicidae) and in vitro stimulation in isolated midguts. Insect Biochemistry, 1989, 19, 129-137.

Gregorio E.A. \& Ratcliffe N.A. The distribution of agglutinins and lytic activity against Trypanosoma rangeli and erythrocytes in Rhodnius prolixus and Triatoma infestans tissue extracts and haemolymph. Memoares do Instituto Oswaldo Cruz, 1991, 86, 181-186.

Grubhoffer L. \& Durnová E. A lectin in salivary glands of the tick Ixodes ricinus: detection and partial characterization. XX. International Congress of Entomology, Firenze, Italy, August 25-31, 1996, Proceedings, 1996, 746.

Grubhoffer L., Hypša V., Uhlíř J. \& KuHn K.-H. New tissue lectins (agglutinins) of vectors: survey of their characteristics. ICOPA VIII, Izmir, October 10-14, 1994, Abstracts, Vol. 2, 262.

GRUBHOFFER L. \& MAŤHA V. New lectins of invertebrates. Zoological Science (Tokyo), 1991, 8, 1001-1003.

Grubhoffer L., MaŤHa M. \& Volf P. Midgut hemagglutinins in five species of tsetse flies (Glossina spp.): two different lectin systems in the midgut of Glossina tachinoides. Folia Parasitologica, 1994, 41, 229-232.

Grubhoffer L. \& Noriega G.F. Midgut lectins of the mosquito Aedes aegypti. Journal of Cellular Biochemistry, 1995, 21A, 207.

Grubhoffer L., Vereš J. \& Dusbábek F. Lectins as the molecular factors of recognition and defence reaction of ticks. In: Modern Acarology, Vol. 2, Dusbábek F. \& Bukva V. (eds.), Academia, Prague and SPB Academic Publishing bv., The Hague, 1991, 381-388.
Grubhoffer L. \& Wells M.A. Lectin (Hemagglutinin) activity in midgut of the mosquito Aedes aegypti: partial characterization and perspectives. Poster HexaPodium, Center for Insect Science, University of Arizona, Tucson, Abstract 29, 1993.

Ham P.J., Phiri J.S. \& Nolan G.P. Effect of N-acetyl-D-glucosamine on the migration of Brugia pahangi microfilariae into the haemocoel of Aedes aegypti. Medical and Veterinary Entomology, 1991, 5, 485-493.

HulínsKÁ D., Volf P. \& Grubhoffer L. Characterization of Borrelia burgdorferi glycoconjugates and surface carbohydrates. Zentralblatt für Bakteriologie Mikrobiologie und Hygiene [A], 1992, 276, 473-480.

Hypša V. \& GRUBhOFFER L. An LPS-binding hemagglutinin in the midgut of Triatoma infestans: partial characterization and tissue localization. Archives of Insect Biochemistry and Physiology, 1995, 28, 247-255.

IBrahim E.A.R., Ingram G.A. \& Molyneux D.H. Haemagglutinins and parasite agglutinins in haemolymph and gut of Glossina. Tropical Medicine and Parasitology, 1984, 35, 151-156.

Ingram G.A., EAST J. \& MOlyneux D.H. Naturally occurring agglutinins against trypanosomatid flagellates in the hemolymph of insects. Parasitology, 1984, 89, 435-451.

IngRAM G.A. \& Molyneux D.H. Insect lectins: role in parasite-vector interactions. In: Lectin Reviews, Vol. 1, Kilpatric D.C., Van Driessche E. \& Bog-Hansen T.C. (eds.), 1991, 103-127.

Ingram G.A. \& Molyneux D.H. Lectins (haemagglutinins) in the haemolymph of Glossina fuscipes fuscipes: isolation, partial characterization, selected physio-chemical properties and carbohydrate-binding specificities. Insect Biochemistry, 1990, 20, 13-27.

Ingram G.A. \& Molyneux D.H. Sugar specificities of antihuman $\mathrm{ABO}(\mathrm{H})$ blood group erythrocyte agglutinins (lectins) and haemolytic activity in the haemolymph and gut extracts of three Glossina species. Insect Biochemistry, 1988, 18, 269-279.

Isola E.L.D., LAmmel E.M. \& CAPPa S.M.G. Trypanosoma cruzi: differentiation after interaction of epimastigotes and Triatoma infestans intestinal homogenate. Experimental Parasitology, 1986a, 62, 329-335.

Isola E.L.D., Lammel E.M., Giovanniello O., Katzin A.M. \& Cappa S.M.G. Trypanosoma cruzi morphogenesis: preliminary purification of an active fraction from hemolymph and intestinal homogenate of Triatoma infestans. Journal of Parasitology, 1986b, 72, 467-469.

Isola E.L.D., Lammel E.M., Katzin V.J. \& Cappa S.M.G. Influence of organ extracts of Triatoma infestans on differentiation of Trypanosoma cruzi. The Journal of Parasitology, 1981, 67, 53-58

JaCOBSOn R.L. \& DOYle R.J. Lectin-parasite interactions. Parasitology Today, 1996, 12, 55-60.

JOMORI T., Kubo T. \& Natori S. Purification and characterization of lipopolysaccharide-binding protein from hemolymph of American cockroach Periplaneta americana. European Journal of Biochemistry, 1990, 190, 201-206.

Kamwendo S.P., Ingram G.A., Musisi F.L. \& Molyneux D.H. Haemagglutinin activity in tick (Rhipicephalus appendi- 
culatus) haemolymph and extracts of gut and salivary glands. Annals of Tropical Medicine and Parasitology, 1993, 87, 303-305.

Kamwendo S.P., Musisi F.L., Trees A.J. \& Molyneux D.H. Effect of haemagglutinin (lectin) inhibitory sugars in Theileria parva infection in Rhipicephalus appendiculatus. International Journal for Parasitology, 1995, 25, 29-35.

KARP R.D. Inducible humoral immune defense responses in insects. In: Invertebrate Immunology, Rinkevich B. \& Müller W.E.G. (eds.), Springer-Verlag, Berlin, Heidelberg, New York, 1996, 67-87.

KeTtERIDGE D.S. Lipopolysaccharide from Trypanosoma cruzi. Transactions of the Royal Society of Tropical Medicine and Hygiene, 1978, 72, 101-102.

Kingsolver J.G. \& Daniel T.L. Mechanics of food handling by fluid-feeding insects. In: Regulatory Mechanisms in Insect Feeding, Chapman R.F. \& De Boer G. (eds.), Chapman \& Hall, 1995, 32-68.

Kobayashi M., HiraOKa T. \& Agui N. Biological role of lectin in the humoral defence responses of mosquitoes. Developmental and Comparative Immunology, 1994, 18, S102.

Kobayashi M. \& Yamamoto M. Hemagglutinin in the hemolymph of mosquito Armigeres subalbatus, mediates in vitro melanization of microfilariae, Brugia pahangi. Animal Biology, 1993, 2, 76-78.

Kocourek J. \& Hořejší V. Defining a lectin. Nature, 1981, 290, 188.

Komano H. Antigenic stimulation of hemagglutinin production in insects. In: Immunology of Insects and other arthropods, Gupta A.P. (ed.), CRC Press Inc., Boca Raton, 1991, 403-415.

KuHn K.-H., Uhlíř J. \& GrubhOFFer L. Ultrastructural localization of a sialic-specific hemolymph lectin in hemocytes and other tissues of the hard tick Ixodes ricinus (Acari: Ixodidae). Parasitology Research, 1996, 82, 215-221.

LACKiE A.M. \& VASTA G.R. The role of a galactosyl-binding lectin in the cellular immune response of the cockroach Periplaneta americana (Dictyoptera). Immunology, 1988, 64, 353-357.

LEE Y.C. Biochemistry of carbohydrate-protein interaction. FASEB Journal, 1992, 6, 3193-3200.

LeHane M.J. Biology of blood-sucking insects. Chapters No. 5, 6. Harper Collins Academic, London, 1991, 52-110.

Lehane M.J. The formation and histochemical structure of the peritrophic membrane in the stablefly, Stomoxys calcitrans. Journal of Insect Physiology, 1976, 22, 1551-1557.

Lehane M.J. \& Msangi A.R. Lectin and peritrophic membrane development in the gut Glossina m. morsitans and a discussion of their role in protecting the fly against trypanosome infection. Medical Veterinary Entomology, 1991, 5, 495-501.

Ludwig G.V., Israel B.A., Christensen B.M., Yuill T.M. \& Schultz K.T. Role of La Crosse virus glycoproteins in attachment of virus to host cells. Virology, 1991, 181, 564571.
Maudin I. Inheritance of susceptibility to Trypanosoma congolense infection in Glossina morsitans. Annals of Tropical Medicine and Parasitology, 1982, 76, 225-227.

MAUdLIN I. Transmission of African trypanosomiasis: interactions among tsetse immune system, symbionts and parasites. In: Advances in Disease Vector Research, Harris K.F. (ed.), Springer-Verlag, New York, Inc., 1991, 117-148.

Maudlin I. \& ElLis D.S. Association between intracellular rickettsial-like infections of midgut cells and susceptibility to Trypanosoma infection in Glossina spp. Zeitschrift für Parasitenkunde, 1985, 71, 683-687.

Maudin I. \& Welburn S.C. Lectin mediated establishment of midgut infections of Trypanosoma congolense and Trypanosoma brucei in Glossina morsitans. Tropical Medicine and Parasitology, 1987, 38, 167-170.

Maudin I. \& Welburn S.C. Tsetse immunity and the transmission of trypanosomiasis. Parasitology Today, 1988, 4, 109-111.

Maudlin I., Welburn S.C. \& Mehlitz D. The relationship between rickettsia-like-organisms and trypanosome infections in natural populations of tsetse in Liberia. Tropical Medicine and Parasitology, 1990, 41, 265-267.

McConville M., Turco S.J., Ferguson M.A. \& Sachs D.L. Developmental modification of lipophosphoglycan during the differentiation of Leishmania major promastigotes to an infectious stage. EMBO Journal, 1992, 11, 3593-3600.

Mello C.B., Azambuja P., Garcia E.S. \& Ractliffe N.A. Differential in vitro and in vivo behaviour of three strains of Trypanosoma cruzi in the gut and hemolymph of Rhodnius prolixus. Experimental Parasitology, 1996, 82, 112-121.

Mello C.B., Garcia E.S., Ratcliffe N.A. \& Azambuja P. Trypanosomna cruzi and Trypanosoma rangeli: interplay with hemolymph components of Rhodnius prolixus. Journal of Invertabrate Pathology, 1995, 65, 261-268.

Minnick M.E., Rupp R.A. \& SPENCE K.D. A bacterial induced lectin which triggers hemocyte coagulation in Manduca sexta. Biochemical and Biophysical Research Communications, 1986, 137, 729-736.

Mohamed H.A. \& Ingram G.A. Effects of physico-chemical treatments on hemagglutination activity of Anopheles gambiae hemolymph and midgut extract. Medical Veterinary Entomology, 1994, 8, 8-14.

Mohamed H.A., Ingram G.A. \& Molyneux D.H. Carbohydratebinding specificities of anti-erythrocyte lectins (haemagglutinins) in Anopheles gambiae gut extracts and haemolymph. Medical Veterinary Entomology, 1992, 6, 217-224.

MoloO S.K. \& SHAW M.K. Rickettsial infections of midgut cells are not associated with susceptibility of Glossina morsitans centralis to Trypanosoma congolense infection. Acta Tropica, 1989, 46, 223-227.

Molyneux D.H. The attachment of Trypanosoma guayi in the hindgut of Glossina. Protozoology, 1977, 3, 83-86.

Mori M., Ohyare M., Ito M., Iwamoto S.-I., Matsumoto T., Sumida M. \& Matsubara F. Induction of a hemagglutinating activity in the hemolymph of the silkworm, Bombyx mori, infected with cytoplasmic polyhedrosis virus. Journal of Invertebrate Pathology, 1989, 54, 112-116. 
Natori S. Defence molecules in host defense and development of insects. In: Phylogenetic Perspectives in Immunity: The Insect Host Defense, Hoffmann J.A., Janeway Ch.A., Jr. \& Natori S. (eds.), R.G. Landes Company, Austin, CRC Press, Boca Raton, 1994, 67-73.

NATORI S. \& KuBo T. Role of lectins in development and morphogenesis in insects. In: New Directions in Invertebrate Immunology, Söderhäll K., Iwanaga S. \& Vasta G.R. (eds.), SOS Publications, 1996, 175-188.

NAYAR J.K. \& Sehdal S.S. Hemagglutinating activity in tissue extracts of strains of Anopheles quadrimaculatus and Aedes aegypti susceptible and refractory to Brugia malayi. In: Host Regulated Developmental Mechanisms in Vector Arthropods, Borovsky D. \& Spielman D. (eds.), University of Florida, Vero Beach, 1993, 277-287.

Noriega F.G., Barillas-Mury C.V. \& Wells M.A. Dietary control of late-trypsin gene transcription in Aedes aegypti. Insect Biochemistry and Molecular Biology, 1994, 24, 627631.

OfEK I. \& SHARON N. Lectinophagocytosis: a molecular mechanism of recognition between cell surface sugars and lectins in the phagocytosis of bacteria. Infection and Immunity, 1988, 56, 539-547.

OLAFSEN J.A. Invertebrate lectins: biochemical heterogeneity as a possible key to their biological function. In: Immunity in Invertebrates, Brehélin M. (ed.), Springer-Verlag, Berlin, Heidelberg, 1986, 95-111.

OLAFSEN J.A. Lectins: models of natural and induced molecules in invertebrates. In: Advances in Comparative \& Environmental Physiology, Vol. 24, Cooper E.L. (ed.), SpringerVerlag, Berlin, Heidelberg, 1996, 49-76.

Osir E.O., Abubakar L. \& Imbuga M.O. Purification and characterization of a midgut lectin-trypsin complex from the tsetse fly Glossina longipennis. Parasitology Research, 1995, 81, 276-281.

Osir E.O., Imbuga M.O. \& Onyango P. Inhibition of Glossina morsitans midgut trypsin activity by D-glucosamine. Parasitology Research, 1993, 79, 93-97.

PalánOVÁ L. \& Volf P. Carbohydrate-binding specificities and physico-chemical properties of lectins in various tissue of phlebotominae sandflies. Folia Parasitologica, 1997, 44, 71-76.

PATHAK J.P.N. Haemagglutinins (Lectins) in insects. In: Insect immunity. Series Entomologica, Vol. 48, Pathak J.P.N. (ed.), Kluwer Academic Publishers and Oxford \& IBH Publishing Co. Pvt. Ltd., 1993, 149-169.

PEARSON M.A. Scavenger receptors in innate immunity. Current Opinion in Immunology, 1996, 8, 20-28.

Pereira M.A.E., ANDrade A.F.B. \& Ribeiro J.M.C. Lectins of distinct specificity in Rhodnius prolixus interact selectively with Trypanosoma cruzi. Science, 1981, 211, 597-600.

Peters W. Peritrophic membranes. Springer-Verlag, New York, 1992, 123-233.

Peters W., Kolb H. \& Kolb-Bachofen V. Evidence for a sugar receptor (lectin) in the perithrophic membrane of the blowfly larva, Calliphora erythrocephala Mg. (Diptera). Journal of Insect Physiology, 1983, 29, 275-280.
Peumans W.J. \& Van Damme E.J.M. Lectins as plant defence proteins. Plant Physiology, 1995, 109, 347-352.

Pimenta P.F.P., Saraiva E.M.B., Rowton E., Modi G.B., Garraway L.A., Beverley S.M., Turco S.J. \& Sachs D.L. Evidence that the vectorial competence of phlebotominae sandflies for different Leishmania is controlled by structural polymorphisms in the surface lipophosphoglycan. Proceedings of the National Academy of Sciences of the USA 91, 1994, 9155-9159.

Pimenta P.F.P., Turco S.J., McConville M.J., Lawyer P.G., Perkins P.V. \& SACHS D.L. Stage-specific adhesion of Leishmania promastigotes on the sandfly midgut. Science, 1992, 256, 1812-1815.

Ratcliffe N.A., Nigam Y., Mello C.B., Garcia E.S. \& AzamBUJA P. Trypanosoma cruzi and erythrocyte agglutinins: a comparative study of occurrence and properties in the gut and hemolymph of Rhodnius prolixus. Experimental Parasitology, 1996, 83, 83-93.

RATCliffe N.A. \& Rowley A.F. Insect responses to parasites and other pathogens. In: Immune responses in parasitic infections, Vol. 4, Soulsby E.J.L. (ed.), CRC Press Inc., Boca Raton, 1987, 271-332.

Romoser W.S. The vector alimentary system. In: The Biology of Disease Vectors, Beaty B.J. \& Marquardt W.C. (eds.), University Press of Colorado, Niwot, 1996, 298-317.

SCHLEIN Y. \& JACOBSON R.L. Mortality of Leishmania major in Phlebotomus papatasi caused by plant feeding of the sandflies. American Journal of Tropical Medicine and Hygiene, 1994, 50, 20-27.

Schotтelius J. Neoglycoproteins as tools for detection of carbohydrate-specific receptors on the cell surface of Leishmania. Parasitology Research, 1992, 78, 309-315.

SHARON N. \& Lis H. A century of lectin research (1888-1988). Trends in Biochemical Sciences, 1988, 12, 488-491.

Sharon N. \& Lis H Lectins. Chapman and Hall, London, New York, 1989, 2-127.

Š́ma P. \& VĚTviČKa V. Evolution of Immune Reactions. CRC Press, Inc., Boca Raton, 1990, 59-61.

SLIFKIN M. \& DOYLE R.J. Lectins and their application to clinical microbiology. Clinical Microbiology Reviews, 1990, 3, 197-217.

Smail A.J. \& Haм P. Onchocerca induced hemolymph lectins in blackflies: confirmation by sugar inhibition of erythrocyte agglutination. Tropical Medicine and Parasitology, 1989, 39, 82-83

Souza W. \& Meyer H. An electron microscopic and cytochemical study of the cell coat of Trypanosoma cruzi in tissue cultures. Zeitschrift für Parasitenkunde, 1975, 46, 179-187.

Stiles J.K., Ingram G.A., Wallbanks K.R., Molyneux D.H., Maudin I. \& Welburn S.C. Identification of midgut trypanolysin and trypanoagglutinin in Glossina palpalis spp. (Diptera: Glossinidae). Parasitology, 1990, 101, 369-376.

Svobodová M., Bates P.A. \& Volf P. Detection of lectin activity in Leishmania promastigotes and amastigotes by agglutination methods. Acta Tropica, 1997, 64 (in press). 
Svobodová M., Capo C. \& Mege J.L. A biological role for haemagglutination activity of Leishmania promastigotes and amastigotes. Parasite, 1997, 4, 245-251.

Svobodová M., Volf P. \& Killick-Kendrick R. Agglutination of Leishmania promastigotes by midgut lectins from various species of phlebotominae sandflies. Annals of Tropical Medicine and Parasitology, 1996, 90, 329-336.

Uhlír J., Grubhoffer L., Borský I. \& Dusbábek F. Antigens and glycoproteins of larvae, nymphs and adults of the tick Ixodes ricinus. Medical Veterinary Entomology, 1994, 8, 141-150.

Uhlír J., Grubhoffer L. \& Volf P. Novel agglutinin in the midgut of the tick Ixodes ricinus. Folia Parasitologica, 1996, 43, 233-239.

Van den Abbeele J., Rolin S., Claes Y., Le Ray D., Pays E. \& Coosemans M. Trypanosoma brucei: stimulation of adenylate cyclase by proventriculus and esophagus tissue of the tsetse fly, Glossina morsitans morsitans. Experimental Parasitology, 1995, 81, 618-620.

Van den Abbeele J., van Driessche E., Claes Y., Le Ray D. \& CoOsemans M. Trypanosome-binding proteins of the tsetse flies Glossina palpalis gambiensis and G. morsitans morsitans. International Journal for Parasitology, 1996, 26, 113-116.

VASTA G.R. Invertebrate lectins: distribution, synthesis, molecular biology and function. In: Glycoconjugates: composition, structure and function, Allen H.J. \& Kisailus E.C. (eds.), Marcel Dekker, New York, 1992, 593-684.

VASTA G.R. The multiple biological roles of invertebrate lectins: their participation in nonself recognition mechanisms. In: Phylogenesis of immune functions, Warr G.W. \& Cohen N. (eds.), CRC Press Inc., Boca Raton, 1991, 183-199.

VASTA G.R. \& Marchalonis J.J. Summation: immunological significance of invertebrate lectins. Progress in Clinical Biological Research, 1984, 157, 177-191.

Vereš J. \& Grubhoffer L. Detection and partial characterization of a new plasma lectin in the hemolymph of the tick Ornithodoros tartakouskyi. Microbios Letters, 1991, 45, 61-64.

ViCKERMAN K. The mode of attachment of Trypanosoma vivax in the protoscis of the tsetse fly Glossina fuscipes: an ultrastructural study of the epimastigote stage of the trypanosome. Journal of Protozoology, 1973, 20, 394-424.

Volf P. Lectin activity in the gut extract of sandfly Lutzomyia longipalpis. Folia Parasitologica, 1993, 40, 155-156.

Volf P., GrubHOfFer L. \& MuŠKa M. Detection and identification of tissue specific lectins of the tsetse fly, Glossina tachinoides. Midgut lectin activity with lipopolysaccharide binding specificity. In: Proceedings of an International Symposium on Management of Insect Pests: Nuclear and Related Molecular and Genetic Techniques, International Atomic Energy Agency, Vienna, 1993, 557-565.

Volf P., Kiewegovǎ A. \& Svobodovă M. Sandfly midgut lectin: effect of galactosamine on Leishmania major infections. Medical and Veterinary Entomology, 1997, 11 (in press).

Volf P. \& Killick-Kendrick R. Post-engorgement dynamics of haemagglutination activity in the midgut of six species of phlebotominae sandflies. Medical Veterinary Entomology, $1996,10,247-250$.

Volf P., Killick-Kendrick R., Bates P. \& Molyneux D.H. Comparison of the haemagglutination activities in the gut and head extracts of various species and geographical populations of phlebotominae sandflies. Annals of Tropical Medicine and Parasitology, 1994, 88 (3), 337-340.

Volf P. \& PALǍnOVă L. \& Svobodovă M. Midgut lectins of sandflies. Boletin de la Direccion de Malariología y Saneamiento Ambiental, 1995, 35, Suppl. 1, 371-373.

VOlF P. \& PALǍNOVǍ L. The relationship between protein content of meal and lectin secretion in Pblebotomus duboscqi midgut. Annals of Tropical Medicine and Parasitology, 1996, 90, 567-570.

Wallbanks K.R., Ingram G.A. \& Molyneux D.H. The agglutination of erythrocytes and Leishmania parasites by sandfly gut extracts: evidence for lectin activity.Tropical Medicine and Parasitology, 1986, 37, 409-413.

Welburn S.C., Arnold K., Maudlin I. \& Gooday G.W. Rickettsia-like organisms and chitinase production in relation to transmission of trypanosomes by tsetse flies. Parasitology, 1993, 107, 141-145.

WeLbURN S.C. \& MAUDLIN I. Lectin mediated control of establishment of midgut infections of Trypanosoma congolense and T. bruce i in tsetse and the role of midgut and haemolymph lectins in trypanosome maturation. 2nd International Symposium on Molecular Insect Science, Flagstaff, Arizona, 1993, Proceedings, 181.

WELBURN S.C. \& MAUdLIN I. Lectin signalling of maturation of T. congolense infections in tsetse. Medical and Veterinary Entomology, 1989, 3, 141-145.

WeLburn S.C. \& Maudin I. The nature of the teneral state in Glossina and its role in the acquisition of trypanosome infection in tsetse. Annals of Tropical Medicine and Parasitology, 1992, 86, 529-536.

WelBuRn S.C., Maudun I. \& Eluis D.S. Rate of trypanosome killing by lectins in midguts of different species and strains of Glossina. Medical and Veterinary Entomology, 1989, 3, 77-82.

Welburn S.C., Maudun I. \& Molyneux D.H. Midgut lectin activity and sugar specificity in teneral and fed tsetse. Medical and Veterinary Entomology, 1994, 8, 81-87.

Wiggesworth V.B. Symbiotic bacteria in a blood-sucking insect, Rbodnius prolixus Stahl (Hemiptera, Triatominae). Parasitology, 1936, 28, 284-289.

YEATON R.W. Occurrence of nonlymphatic hemagglutinins in arthropods and their possible functions. In: Hemocytes and Humoral Immunity in Arthropods, Gupta P. (ed.), Wiley, New York, 1986, 505-516.

YoshinO T.P. \& VASTA G.R. Parasite-invertebrate host immune interactions. In: Advances in Comparative \& Environmental Physiology, Vol. 24, Cooper E.L. (ed.), SpringerVerlag, Berlin, 125-167.

YoshIZAKI N. Functions and properties of animal lectins. Zoological Science (Tokyo), 1990, 7, 581-591. 